\title{
Balancing the Risks of Bleeding and Stent Thrombosis: A Decision Analytic Model to Compare Duration of Dual Antiplatelet Therapy after Drug-Eluting Stents
}

\author{
Pallav Garg, MBBS, MSc ${ }^{\star}$, Benjamin Z. Galper, MD, MPH${ }^{\star}$, David J. Cohen, MD, MSc, Robert \\ W. Yeh, MD, MSc, and Laura Mauri, MD, MSc \\ Divisions of Cardiology, London Health Sciences Center, London, Ontario (P.G.); Brigham and \\ Women's Hospital, Harvard Medical School, Boston, MA (B.Z.G., L.M.); Saint Luke's Mid-America \\ Heart Institute, University of Missouri-Kansas City, Kansas City, MO (D.J.C.); Massachusetts \\ General Medical Hospital, Harvard Medical School, Boston, MA (R.W.Y.) and Harvard Clinical \\ Research Institute (R.W.Y., L.M.), Boston, MA
}

\begin{abstract}
Background-After coronary stent placement, whether dual antiplatelet therapy (DAPT) duration should be extended to prevent late stent thrombosis (ST) or adverse cardiovascular events is uncertain.
\end{abstract}

\begin{abstract}
Methods-To define the reduction in ischemic events required to outweigh increased bleeding with longer-duration DAPT, we developed a decision-analytic Markov model comparing DAPT durations of 6,12, and 30 months after DES. Separate models were developed for patients presenting with and without an acute-coronary syndrome (ACS). We used sensitivity analyses to identify the incremental benefit of longer-duration DAPT on either ST or the composite of cardiac death, myocardial infarction and ischemic stroke (MACCE) required to outweigh the increased risk of bleeding associated with longer DAPT. The outcome from each strategy was quantified in terms of quality-adjusted life years (QALYs).
\end{abstract}

\begin{abstract}
Results-In the non-ACS population, in order for 30 months of DAPT to be preferred over 12 months of therapy, DAPT would have to result in $78 \%$ reduction in the risk of ST (relative risk, RR, $0.22 ; 3.1$ fewer events per 1000) and only a 5\% reduction in MACCE (RR 0.95; 2.2 fewer events per 1000) as compared to aspirin alone. For the ACS population, DAPT would have to result in $44 \%$ reduction in the risk of ST (RR, $0.56 ; 3.4$ fewer events per 1000) but only a $2 \%$ reduction in MACCE (RR 0.98; 2.3 fewer events per 1000) as compared to aspirin alone, for 30 months of DAPT to be preferred over 12 months.
\end{abstract}

\footnotetext{
Address for Correspondence: Dr. Laura Mauri, 75 Francis St. Boston Massachusetts 02115, lmauri1 @ partners.org, Phone: 617-732-8936; fax 617-525-8027.

*Co-First Authors

Disclosures

Dr. Galper reports receiving research grant support from the NIH training grant (T32 HL007604). Dr. Yeh reports receiving grant support from the National Heart, Lung, and Blood Institute (1K23HL118138) and the Hassenfeld Scholars Program, and consulting fees from Abbott Vascular and Gilead Sciences. Dr. Mauri reports grant support from Abbott, Boston Scientific, Cordis, Medtronic, Eli Lilly, Daiichi-Sankyo, Bristol-Myers Squibb, and Sanofi-Aventis, as well as consulting fees from Biotronik, Medtronic, and St. Jude. Dr. Cohen receives research grant support from Medtronic, Abbott Vascular, Boston Scientific, Astra-Zeneca, and Eli Lilly, and Daichii-Sankyo. Dr. Cohen also receives consulting fees from Medtronic, Abbott Vascular, Astra-Zeneca, and Eli Lilly.
} 
Conclusions-Small absolute differences in the risk of ischemic events with longer DAPT would be sufficient to outweigh the known bleeding risks.

\section{Keywords}

stents; revascularization; platelets; ischemia; hemorrhage

\section{Introduction}

While stent thrombosis (ST) is a rare event after percutaneous coronary intervention (PCI) with drug eluting stents (DES), the morbidity and mortality from ST remains high. ${ }^{1}$, 2 The use of dual antiplatelet therapy (DAPT) has been shown to reduce the rate of ST in the first few months after PCI with a DES but the effect of DAPT on late and especially very-late ST (VLST) is less certain..$^{3,4}$ The appropriate duration of DAPT after PCI with DES is therefore an area of ongoing investigation. While the association between longer treatment with DAPT and an increased risk of bleeding is well recognized, decreased risks of ischemic events such as stent thrombosis (ST) with longer duration DAPT are less evident, ${ }^{5-7}$ and recent studies that have compared short-term and long-term DAPT have been underpowered to detect differences in ST risk. ${ }^{8-13}$ Furthermore, adverse cardiovascular events, such as plaque rupture beyond the stented segment, are more frequent late events than ST, and it is therefore also important to consider the impact of potential risk reduction in cardiac death, MI, and stroke attributable to longer-duration DAPT. ${ }^{14,15}$

Decision analysis is a tool for combining data from multiple sources that can be useful in guiding complex medical decisions, especially when there is uncertainty regarding one or more key parameters. The optimal duration of DAPT post-PCI is a complex medical decision that must balance the risks of bleeding on DAPT with the expected benefit in ischemic event reduction from DAPT. A decision analytic model that can simultaneously assess the risks of bleeding and ischemia on DAPT is ideally suited to determine the threshold risk reduction in ischemic events required to make longer-duration DAPT a preferred strategy. We, therefore, developed a decision analytic Markov model to compare DAPT durations of 6,12 , and 30 months post-PCI with DES in order to identify the magnitude of reduction in ischemic events that would outweigh the expected increased bleeding risk from longer-duration DAPT.

\section{Methods}

A Markov model simulates transitions between distinct health states that would occur over a lifetime in a cohort of patients undergoing a selected treatment strategy. ${ }^{16,17}$ We derived treatment related morbidity and mortality probabilities from published literature, and assessed the outcome of treatment in terms of quality-adjusted life years (QALYs).

There is considerable uncertainty regarding whether there is an ischemic benefit with longer DAPT duration, either via reduction in stent-related events or ischemic events unrelated to the stent. Therefore, we did not seek to determine whether there is a benefit of longerduration DAPT. Our base-case model did not assume any benefit of DAPT on ischemic endpoint of ST or the composite of cardiac death, myocardial infarction and ischemic stroke 
(MACCE). We used the decision analytic model to solve for the threshold of benefit of longer DAPT duration on either ST or MACCE that would be required to outweigh the increased risk of bleeding associated with longer-duration DAPT.

\section{Patient Population}

Our model was designed to be applied to a patient undergoing PCI with DES. As patients with and without ACS have different risks of ischemic and bleeding events post-PCI, we constructed separate decision analytic models for these populations. ${ }^{18}$ For the non-ACS population model patients were treated with DAPT for 6,12 , or 30 months following PCI. Since guidelines recommend 12 months of DAPT for any patient presenting with ACS, ${ }^{19}$ only DAPT durations of 12 and 30 months were evaluated in the ACS population model. DAPT was assumed to be treatment with clopidogrel $75 \mathrm{mg}$ daily and low-dose aspirin. Where possible, the characteristics of the patient population were chosen to match those of contemporary population-based PCI registries.

\section{Decision Model Structure}

Figure 1A depicts the outcomes of the chosen strategy in the form of a decision tree. During the initial 6-month follow-up period, patients could experience non-cardiac death or cardiac death unrelated to ST. In the absence of these events, patients were at risk for ST or nonfatal MI (non-ST related). All patients with stent thrombosis were assumed to suffer a fatal or non-fatal MI and were at risk of sudden cardiac death. ${ }^{3,4}$ All patients were at risk of bleeding events, including fatal bleed, hemorrhagic stroke, major bleed (noncerebrovascular), minor bleed, as well as ischemic stroke.

During the ensuing 6-month periods, survivors of the first 6 months following the index procedure were at risk of the same events, in addition to background risks of non-cardiac and cardiac mortality. We assumed that patients could experience one ischemic and one bleeding event for every 6 months following the index PCI procedure.

The Markov model that describes potential health states and transitions after the index PCI on DAPT is depicted in Figure 1B. The specific health states that we considered included: (1) Survivors with ST; (2) Survivors with non-fatal MI; (3) Survivors with hemorrhagic stroke; (4) Survivors without events; and (5) Death. Each of these health states were further stratified according to the presence or absence of a prior major bleeding event, whether an individual was on DAPT, and the presence of a prior event requiring further DAPT (e.g. ST or non-fatal MI). In each health state, during each 6 month cycle, we modelled ST, non-fatal MI and ischemic stroke in addition to cardiac death and non-cardiac death as well as bleeding events. Upon completing the assigned DAPT duration without further ischemic events, patients were assumed to continue aspirin monotherapy for the remainder of their life. Patients surviving an ischemic event such as ST or non-fatal MI were assumed to return back to the original DAPT treatment strategy (e.g. further 12 months DAPT if in the 12 month DAPT strategy). Patients who suffered a hemorrhagic stroke were assumed to be treated with aspirin alone in the long-term. Patients who suffered major or minor bleeding were continued on DAPT for the duration of the term. The model was run until all patients have died (lifetime horizon). 


\section{Ischemic Events Estimates}

To determine the probability of ischemic events post-PCI, separate meta-analyses of the literature on ischemic outcomes after PCI were performed for patients initially presenting with or without ACS (Table 1 and Supplemental Appendix). Studies that did not distinguish patients with and without ACS were not included. We observed in our meta-analyses that ischemic event probabilities other than VLST were relatively constant beyond 6-months after PCI. Thus, except for VLST, all 6-month ischemic event probabilities beyond 12 months following PCI were assumed to be constant and identical to the 6-12 month event probabilities derived from meta-analyses (Table 1). The ischemic event probabilities beyond 6-months after PCI were assumed to reflect the probabilities of ischemic events for patients off DAPT. The true effect of DAPT duration on the relative risk of ischemic events was not estimated from the literature and was the primary focus of our sensitivity analyses.

\section{Bleeding Events Estimates}

In order to determine the bleeding event probabilities for patients on and off DAPT we performed meta-analyses of the literature on bleeding outcomes for patients on DAPT and for patients on aspirin alone (Table 1; Supplemental Appendix). The severity of noncerebrovascular bleeding events was determined based on the Thrombolysis in Myocardial Infarction (TIMI) bleeding risk score. Event probabilities for TIMI major and TIMI minor bleeding post-PCI were determined from the literature and used as the probabilities of major and minor bleeding in our model (Table 1; Supplemental Appendix). Based on our metaanalyses, we assumed that the probability of bleeding events beyond the first 6-months after PCI were constant (Table 1).

\section{Relative Risks of Future Events}

Estimates of the effects of ischemic events on subsequent risks of cardiac events and death and of the effects of bleeding events on short and long-term mortality were estimated from the literature and are shown in Table 2. We assumed a ST event was associated with a longterm increase in future ST risk, and that both ST and MI were associated with an increased risk of long-term cardiac death. ${ }^{2,17,20,21}$ Patients with major bleeding on DAPT were assumed to have an increased risk of recurrent bleeding on DAPT (Table 2). ${ }^{22}$ While some studies suggest an association between periprocedural bleeding and future non-cardiac death, ${ }^{23-25}$ this remains uncertain, as patients who suffer periprocedural bleeding events may also have more comorbidities placing them at higher risk of non-cardiac death. ${ }^{26,}{ }^{27}$ In our base-case model, we did not assume an increased risk of future non-cardiac death in patients with prior non-cerebrovascular major bleed, but in sensitivity analysis we explored the impact of varying degrees of increased risk of death related to major bleeding.

\section{Quality-of-Life Adjustments}

The outcomes of each treatment strategy were quantified in terms of QALYs over a patient's lifetime. In this context, 1 year of life without stable angina, revascularization, stroke, or prior MI was assumed to be a year of perfect health and was assigned a value of 1.0 QALY. Patients who entered the ACS and non-ACS model were assigned a baseline quality of life consistent with the quality of life of individuals undergoing PCI in the setting of MI (0.85) 
or in the setting of stable coronary artery disease (0.92) respectively (Table 3). ${ }^{28,} 29$

Subsequent ischemic and bleeding events in the model resulted in a disutility, applied during the year in which the event occurred (Table 3) ${ }^{30-33}$ Both hemorrhagic and ischemic stroke were assumed to result in a life-long reduction in utility (Table 3 ). ${ }^{30,33}$

\section{Primary Analysis}

Our main objective was to determine the threshold relative risk of ST and MACCE associated with longer as compared with shorter-duration DAPT that would outweigh the increased risks of bleeding and its consequences. We therefore performed one-way sensitivity analyses in which we varied the relative risk of ST or MACCE associated with DAPT. Individual components of MACCE were assumed to vary equally in the sensitivity analyses. Relative risks of ST and MACCE were defined as the ratio of risk on DAPT versus aspirin alone. For each of the DAPT duration strategies we calculated quality adjusted life expectancy (QALE) and considered the strategy associated with a higher value to be preferred.

\section{Additional Sensitivity Analyses}

Because our model was based on a number of assumptions, we performed additional deterministic sensitivity analyses to examine whether and how plausible variations in these assumptions and risks would alter our findings. To evaluate the sensitivity of this analysis to assumptions regarding bleeding, we performed two-way sensitivity analyses in which we varied the relative benefit required from longer-DAPT duration in terms of a function of an increasing relative risk of bleeding.

To determine the effect of the variation in each input value on the model outcomes, we performed multiple simultaneous one-way sensitivity analyses in which we varied the values for each of the model inputs based on the $95 \%$ confidence intervals of their expected values as reported in the literature. Microsimulations (1.5 million iterations) were performed over both a lifetime horizon and a 3-year time horizon (to simulate a randomized clinical trial scenario), in order to calculate cumulative ischemic and bleeding absolute risks and absolute risk reduction. Absolute risk reduction was defined as the risk difference in the outcomes of ST and MACCE between longer-duration and shorter-duration DAPT at the threshold relative risk.

The Markov model was designed, and all analyses were performed with TreeAge Pro Suite 2014 software package (TreeAge Software, Inc., Williamstown, Massachusetts). All analyses were deterministic to identify thresholds rather than probabilities that one strategy or another would be optimal. Pooled estimates across publications were calculated with inverse variance weighting using Stata/SE 13.0 (StataCorp, College Station, Texas). 


\section{Results}

\section{Threshold Risk Reduction in Ischemic Events from Longer-Duration DAPT Required to Overcome Bleeding Risk}

The model predicted QALE for a typical 62-year old patient undergoing coronary revascularization with a DES was 16.656 years for the non-ACS population and 13.363 years for the ACS population, assuming no benefit or risk of DAPT over aspirin. Under the assumption of no ischemic benefit of DAPT and base-case bleeding risks, the projected QALE with 12 months of DAPT was 16.639 years in non-ACS population and 13.345 years in the ACS population, and with 30 months of DAPT, the projected QALE was 16.625 and 13.333 years, respectively.

Based on meta-analytic baseline event risks (Table 1) and a relative risk of bleeding events on DAPT of 1.7 (Table 2), the threshold relative risks of ST and MACCE that would be required to make longer duration DAPT preferred over shorter duration DAPT are shown in Table 4. Comparing 30-months versus 12-months of DAPT, the threshold relative risk for MACCE was 0.95 (absolute risk reduction $0.22 \%$ ) for the non-ACS population and 0.98 (absolute risk reduction $0.23 \%$ ) for the ACS population, and the threshold relative risk for ST was 0.22 (absolute risk reduction $0.31 \%$ ) for the non-ACS population and 0.56 (absolute risk reduction $0.34 \%$ ) for the ACS population (Appendix Figures 1 and 2). For the non-ACS population the threshold relative risk for 12-months of DAPT to be preferred over 6-months of DAPT was 0.32 for ST (absolute risk reduction $0.10 \%$ ) and 0.95 for MACCE (absolute risk reduction $0.05 \%$ ).

\section{Influence of Bleeding Risk on Ischemic Risk Reduction Required with Longer DAPT}

As the relative risk of bleeding on DAPT as compared to on aspirin alone increases, the relative risk reduction in ST required to make longer-duration DAPT the preferred approach increases, and does so more substantially for the non-ACS than for the ACS population (Figure 2). In the ACS population, if the relative risk of all types of bleeding from DAPT over aspirin alone was greater than 2.61 (i.e. 54\% increase above the base-case assumptions), no further risk reduction in ST would outweigh the increased bleeding risk and allow for 30-months of DAPT to be preferred over 12-months of DAPT. The comparable relative risk for the non-ACS population is 1.91 (13\% increase above the basecase assumption). However, increasing the relative risk of bleeding had a relatively small effect on the threshold risk reduction for MACCE required to make 30-months of DAPT the preferred strategy in either the non-ACS or ACS populations (Figure 2).

\section{Sensitivity Analyses}

We performed multiple one-way sensitivity analyses to demonstrate the relationship between plausible variations in model assumptions and the preferred DAPT duration strategy for the non-ACS and ACS models (Figures 3A and 3B). For both models, the most influential parameters were the probability of VLST, the risk of death attributable to ST, the relative risk of fatal bleeding and hemorrhagic stroke on DAPT as compared with aspirin alone, the risk of long-term non-cardiac death associated with major non-cerebrovascular 
bleeding events, and the long-term utilities assigned to patients with ST and stroke (Figures $3 \mathrm{~A}$ and $3 \mathrm{~B})$.

Because the attributable risk of mortality following major bleeding is uncertain, we evaluated the sensitivity of our findings to variation in this parameter. Beyond a relative risk of death from a major non-cerebrovascular bleed of 2.81 (85\% increase above the base-case assumption) in the ACS population or 1.84 (21\% increase above the base-case assumption) in the non-ACS population, no relative risk reduction in ST with prolonged DAPT would outweigh the risk of bleeding. In contrast, the threshold relative risk of MACCE was less affected by changing assumptions of mortality following major bleeding. For example, at a relative risk of death from major non-cerebrovascular bleeding of 3.0 (97\% increase above the base-case assumption), the relative risk in MACCE needed to outweigh the risk of bleeding would only need to decrease from 0.98 to 0.93 for the ACS population and from 0.95 from 0.89 for the non-ACS population, respectively. When the disutility associated with non-cerebrovascular major bleeding events was increased ten-fold from 0.025 (Table 3) to 0.25 , there was only a minimal effect on the required relative risk of ST to overcome the risk of bleeding on DAPT for both the ACS and non-ACS populations.

\section{Discussion}

Following coronary stenting, DAPT reduces not only stent thrombosis, but is also associated with reduction in future ischemic events beyond the stented coronary segment compared with aspirin alone. $6,7,19,34-36$ While randomized trials have demonstrated that one-year of treatment with DAPT confers a reduction in the risk of recurrent ischemic events in patients treated for ACS, in patients without ACS, and in all patients beyond one year from PCI, the optimal duration of therapy is unknown. ${ }^{7}, 35$ Specifically, there is uncertainty as to the magnitude of reduction in the risk of ischemic events that can be anticipated from longer therapy, and whether the benefits of any such risk reductions outweigh the expected increase in bleeding risk.

Individual trials have examined DAPT duration after PCI with DES. ${ }^{8-13}$ While each completed study comparing durations of antiplatelet therapy has been powered to compare rates of bleeding between treatment arms, these studies have been relatively underpowered for the endpoint of ST. ${ }^{8-13}$ Furthermore, no trials have directly addressed the balance between ischemic benefit and bleeding, and many trials utilized combined endpoints such as net adverse clinical events in which bleeding and ischemic complications of various severities have been assigned uniform weights. ${ }^{9,}{ }^{11}$ In fact even large trials that are adequately powered typically compare individual endpoints across treatment arms rather than reconciling the relative impacts of multiple potential events, ischemic and bleeding, per patient. ${ }^{37}$ In this study, we used decision analysis in order to reconcile events with varying rates and impacts on subsequent quality of life and life expectancy in order to compare treatment decisions.

Our analysis was designed to define what magnitude of risk reduction in either ST or MACCE would be sufficient to outweigh bleeding risk, as determined by quality-adjusted life expectancy. Under assumptions derived from the current literature, we found that 
absolute risk differences in MACCE or ST of $0.2-0.4 \%$ would be sufficient to outweigh the increased risk of bleeding when comparing 30-months versus 12-months of DAPT. While recent studies have evaluated even shorter DAPT duration post-PCI, ${ }^{9-11}$ our analysis demonstrates that even smaller absolute risk differences in ST of $0.1 \%$ and MACCE of $0.05 \%$ would be needed to outweigh the risk of bleeding to demonstrate that 12 -months of DAPT is preferable over 6-month of DAPT. These results suggest that studies examining longer duration therapy should not conclude that a shorter-term DAPT strategy is noninferior to a long-term strategy unless they are powered to detect such differences in stent thrombosis or global ischemic endpoints. While few trials have been designed to detect differences on either of these types of endpoints of a magnitude of less than $0.5 \%$, the DAPT Study, currently in follow-up, is powered to detect absolute risk differences of $0.275 \%$ for ST and $0.725 \%$ for MACCE over a $12-30$ month period. ${ }^{37}$

Stent thrombosis has a profound impact on mortality and morbidity given its significant association with sudden death and a near universal association with myocardial infarction. Therefore, while it is a rare event, small absolute differences in stent thrombosis are clinically significant. Similarly, the occurrence of death, myocardial infarction, and stroke all have a major impact on QALE. Since these events, taken together, are nearly ten times as frequent as stent thrombosis ( $2.8 \%$ vs $21.2 \%$ at 3 years for ACS and $1.1 \%$ vs $9.3 \%$ at 3 years for non ACS, in our model), even small relative reductions in MACCE risk (e.g. a relative risk of 0.95) are projected to have an important impact on quality adjusted life expectancy, and even smaller relative reductions are meaningful in the setting of ACS (e.g. a relative risk of 0.98).

The estimated thresholds for risk reduction in ST or MACCE determined in our model are, however, sensitive to several factors including relative risk of bleeding, mortality attributable to bleeding, and baseline risks of late and very late ST, each of which are uncertain to varying degrees. Patients who suffer major bleeding events in the periprocedural period have an increased long-term risk of death, yet it remains uncertain what magnitude of long-term risk is directly attributable to bleeding independent of comorbidities that are associated with bleeding and mortality. While two smaller trials demonstrated that the adjusted hazard ratio for death post-PCI in patients suffering periprocedural bleeding may be as high as $3.5,23,25$ a study of over 400,000 patients undergoing PCI demonstrated that the adjusted upper limit of the $95 \%$ confidence interval for the hazard ratio for death in patients suffering periprocedural bleeding after PCI was $1.40 .{ }^{24} \mathrm{We}$ found that a relative risk of death from a non-cerebrovascular major bleeding event of over 2.0 for the non-ACS population and 3.0 for the ACS population would negate any benefit from ST risk reduction from longer-duration. In contrast, conclusions regarding MACCE were relatively insensitive to increasing the risk attributed to bleeding such that it was always possible to identify absolute and relative differences in MACCE that would overshadow the bleeding risks.

Our results are dependent on the absolute rate of events, and recent trials assessing newer generation DES have demonstrated lower absolute rates of ST compared with earlier generation DES. ${ }^{38,39}$ It is expected that with lower absolute stent thrombosis risks, that the 
relative risk reduction in ST needed to overcome the bleeding risk on DAPT would need to be greater.

\section{Study Limitations}

Our model inputs were based on meta-analyses of the literature on ischemic and bleeding event probabilities after PCI, and while we sought to quantify the impact of uncertainty on our model, the results should be interpreted in the context of the design of each of the studies included in the meta-analyses. While studies included in our meta-analysis contained robust patient follow-up for up to 12-months after PCI, the long-term model event probabilities were based on a limited number of studies. The observed risks of events postPCI are slightly different in patients presenting with ST-elevation MI and non-ST elevation MI, yet most of the data supporting the model was obtained from combined ACS populations. While it is possible that a patient could have multiple ischemic and bleeding events, we modeled only one ischemic and/or bleeding event within a 6-month time period. Additionally, we obtained data regarding risks from studies of clopidogrel and aspirin as DAPT, yet other anti-platelet agents such as prasugrel and ticagrelor may have a different risk benefit profile. The quality of life estimates in our model were based on relatively small studies. ${ }^{28-30,32,33}$ While we acknowledge the uncertainty in these quality of life estimates, we expect that the uncertainty would be relatively similar for both bleeding and ischemic utility estimates. We performed deterministic sensitivity analyses, assuming that all quantities are known with absolute precision, to estimate the magnitude of ischemic event reduction required to outweigh the expected bleeding risk on DAPT without making any assumptions of the expected magnitude of ischemic event reduction. As the results of ongoing clinical trials become available, uncertainty in these parameters can be incorporated in future analyses using this model structure. Furthermore, we addressed the inherent uncertainty in the reported data by conducting multiple sensitivity analyses related to the effect of the uncertainty of each of our model inputs on our overall outcomes (Figures 3A and 3B). Lastly, while our model is meant to assess outcomes for a global population of patients undergoing PCI, patient specific factors, such as age, bleeding risk, and likely adherence to medical therapy would play an important role in determining the optimal DAPT duration post-PCI for an individual patient.

\section{Conclusion}

On the basis of a decision analytic model incorporating the best data currently available we found that absolute reductions of less than $0.4 \%$ for ST or MACCE from DAPT would be sufficient to outweigh the bleeding risk from DAPT and make longer-duration DAPT after the implantation of a DES a preferred approach. These findings suggest that in order to compare treatment strategies where there are discordant risks of ischemia and bleeding, trials must be designed to have adequate power to identify differences in ischemic endpoints that might outweigh bleeding risks.

\section{Supplementary Material}

Refer to Web version on PubMed Central for supplementary material. 


\section{References}

1. Palmerini T, Biondi-Zoccai G, Della Riva D, Stettler C, Sangiorgi D, D'Ascenzo F, Kimura T, Briguori C, Sabate M, Kim HS, De Waha A, Kedhi E, Smits PC, Kaiser C, Sardella G, Marullo A, Kirtane AJ, Leon MB, Stone GW. Stent thrombosis with drug-eluting and bare-metal stents: Evidence from a comprehensive network meta-analysis. Lancet. 2012; 379:1393-1402. [PubMed: 22445239]

2. Mauri L, Hsieh WH, Massaro JM, Ho KK, D'Agostino R, Cutlip DE. Stent thrombosis in randomized clinical trials of drug-eluting stents. N Engl J Med. 2007; 356:1020-1029. [PubMed: 17296821]

3. Iakovou I, Schmidt T, Bonizzoni E, Ge L, Sangiorgi GM, Stankovic G, Airoldi F, Chieffo A, Montorfano M, Carlino M, Michev I, Corvaja N, Briguori C, Gerckens U, Grube E, Colombo A. Incidence, predictors, and outcome of thrombosis after successful implantation of drug-eluting stents. JAMA. 2005; 293:2126-2130. [PubMed: 15870416]

4. Cutlip DE, Baim DS, Ho KK, Popma JJ, Lansky AJ, Cohen DJ, Carrozza JP Jr, Chauhan MS, Rodriguez O, Kuntz RE. Stent thrombosis in the modern era: A pooled analysis of multicenter coronary stent clinical trials. Circulation. 2001; 103:1967-1971. [PubMed: 11306525]

5. Bhatt DL, Fox KA, Hacke W, Berger PB, Black HR, Boden WE, Cacoub P, Cohen EA, Creager MA, Easton JD, Flather MD, Haffner SM, Hamm CW, Hankey GJ, Johnston SC, Mak KH, Mas JL, Montalescot G, Pearson TA, Steg PG, Steinhubl SR, Weber MA, Brennan DM, Fabry-Ribaudo L, Booth J, Topol EJ. Clopidogrel and aspirin versus aspirin alone for the prevention of atherothrombotic events. N Engl J Med. 2006; 354:1706-1717. [PubMed: 16531616]

6. Steinhubl SR, Berger PB, Mann JT 3rd, Fry ET, DeLago A, Wilmer C, Topol EJ. Early and sustained dual oral antiplatelet therapy following percutaneous coronary intervention: A randomized controlled trial. JAMA. 2002; 288:2411-2420. [PubMed: 12435254]

7. Yusuf S, Zhao F, Mehta SR, Chrolavicius S, Tognoni G, Fox KK. Effects of clopidogrel in addition to aspirin in patients with acute coronary syndromes without ST-segment elevation. N Engl J Med. 2001; 345:494-50.2. [PubMed: 11519503]

8. Valgimigli M, Campo G, Monti M, Vranckx P, Percoco G, Tumscitz C, Castriota F, Colombo F, Tebaldi M, Fuca G, Kubbajeh M, Cangiano E, Minarelli M, Scalone A, Cavazza C, Frangione A, Borghesi M, Marchesini J, Parrinello G, Ferrari R. Short- versus long-term duration of dualantiplatelet therapy after coronary stenting: A randomized multicenter trial. Circulation. 2012; 125:2015-2026. [PubMed: 22438530]

9. Feres F, Costa RA, Abizaid A, Leon MB, Marin-Neto JA, Botelho RV, King SB 3rd, Negoita M, Liu M, de Paula JE, Mangione JA, Meireles GX, Castello HJ Jr, Nicolela EL Jr, Perin MA, Devito FS, Labrunie A, Salvadori D Jr, Gusmao M, Staico R, Costa JR Jr, de Castro JP, Abizaid AS, Bhatt DL. Three vs twelve months of dual antiplatelet therapy after zotarolimus-eluting stents: The optimize randomized trial. JAMA. 2013; 310:2510-2522. [PubMed: 24177257]

10. Gwon HC, Hahn JY, Park KW, Song YB, Chae IH, Lim DS, Han KR, Choi JH, Choi SH, Kang HJ, Koo BK, Ahn T, Yoon JH, Jeong MH, Hong TJ, Chung WY, Choi YJ, Hur SH, Kwon HM, Jeon DW, Kim BO, Park SH, Lee NH, Jeon HK, Jang Y, Kim HS. Six-month versus 12-month dual antiplatelet therapy after implantation of drug-eluting stents: The efficacy of Xience/Promus versus Cypher to reduce late loss after stenting (Excellent) randomized, multicenter study. Circulation. 2012; 125:505-513. [PubMed: 22179532]

11. Kim BK, Hong MK, Shin DH, Nam CM, Kim JS, Ko YG, Choi D, Kang TS, Park BE, Kang WC, Lee SH, Yoon JH, Hong BK, Kwon HM, Jang Y. A new strategy for discontinuation of dual antiplatelet therapy: The Reset trial (real safety and efficacy of 3-month dual antiplatelet therapy following Endeavor zotarolimus-eluting stent implantation). J Am Coll Cardiol. 2012; 60:13401348. [PubMed: 22999717]

12. Lee CW, Ahn JM, Park DW, Kang SJ, Lee SW, Kim YH, Park SW, Han S, Lee SG, Seong IW, Rha SW, Jeong MH, Lim DS, Yoon JH, Hur SH, Choi YS, Yang JY, Lee NH, Kim HS, Lee BK, Kim KS, Lee SU, Chae JK, Cheong SS, Suh IW, Park HS, Nah DY, Jeon DS, Seung KB, Lee K, Jang JS, Park SJ. Optimal duration of dual antiplatelet therapy after drug-eluting stent implantation: A randomized, controlled trial. Circulation. 2014; 129:304-312. [PubMed: 24097439] 
13. Park SJ, Park DW, Kim YH, Kang SJ, Lee SW, Lee CW, Han KH, Park SW, Yun SC, Lee SG, Rha SW, Seong IW, Jeong MH, Hur SH, Lee NH, Yoon J, Yang JY, Lee BK, Choi YJ, Chung WS, Lim DS, Cheong SS, Kim KS, Chae JK, Nah DY, Jeon DS, Seung KB, Jang JS, Park HS, Lee $\mathrm{K}$. Duration of dual antiplatelet therapy after implantation of drug-eluting stents. N Engl J Med. 2010; 362:1374-1382. [PubMed: 20231231]

14. Bhatt DL, Flather MD, Hacke W, Berger PB, Black HR, Boden WE, Cacoub P, Cohen EA, Creager MA, Easton JD, Hamm CW, Hankey GJ, Johnston SC, Mak KH, Mas JL, Montalescot G, Pearson TA, Steg PG, Steinhubl SR, Weber MA, Fabry-Ribaudo L, Hu T, Topol EJ, Fox KA. Patients with prior myocardial infarction, stroke, or symptomatic peripheral arterial disease in the charisma trial. J Am Coll Cardiol. 2007; 49:1982-1988. [PubMed: 17498584]

15. Cutlip DE, Chhabra AG, Baim DS, Chauhan MS, Marulkar S, Massaro J, Bakhai A, Cohen DJ, Kuntz RE, Ho KK. Beyond restenosis: Five-year clinical outcomes from second-generation coronary stent trials. Circulation. 2004; 110:1226-1230. [PubMed: 15337693]

16. Beck JR, Pauker SG. The markov process in medical prognosis. Med Decis Making. 1983; 3:419458. [PubMed: 6668990]

17. Garg P, Cohen DJ, Gaziano T, Mauri L. Balancing the risks of restenosis and stent thrombosis in bare-metal versus drug-eluting stents: Results of a decision analytic model. J Am Coll Cardiol. 2008; 51:1844-1853. [PubMed: 18466798]

18. Dehmer GJ, Weaver D, Roe MT, Milford-Beland S, Fitzgerald S, Hermann A, Messenger J, Moussa I, Garratt K, Rumsfeld J, Brindis RG. A contemporary view of diagnostic cardiac catheterization and percutaneous coronary intervention in the United States: A report from the cathpci registry of the National Cardiovascular Data Registry, 2010 through june 2011. J Am Coll Cardiol. 2012; 60:2017-2031. [PubMed: 23083784]

19. Jneid H, Anderson JL, Wright RS, Adams CD, Bridges CR, Casey DE Jr, Ettinger SM, Fesmire FM, Ganiats TG, Lincoff AM, Peterson ED, Philippides GJ, Theroux P, Wenger NK, Zidar JP. 2012 ACCF/AHA focused update of the guideline for the management of patients with unstable angina/non-st-elevation myocardial infarction (updating the 2007 guideline and replacing the 2011 focused update): A report of the American College of Cardiology Foundation/American Heart Association task force on practice guidelines. J Am Coll Cardiol. 2012; 60:645-681. [PubMed: 22809746]

20. Cole JH, Miller JI 3rd, Sperling LS, Weintraub WS. Long-term follow-up of coronary artery disease presenting in young adults. J Am Coll Cardiol. 2003; 41:521-528. [PubMed: 12598059]

21. Lloyd-Jones DM, Camargo CA, Allen LA, Giugliano RP, O'Donnell CJ. Predictors of long-term mortality after hospitalization for primary unstable angina pectoris and non-st-elevation myocardial infarction. Am J Cardiol. 2003; 92:1155-1159. [PubMed: 14609588]

22. Chan FK, Ching JY, Hung LC, Wong VW, Leung VK, Kung NN, Hui AJ, Wu JC, Leung WK, Lee VW, Lee KK, Lee YT, Lau JY, To KF, Chan HL, Chung SC, Sung JJ. Clopidogrel versus aspirin and esomeprazole to prevent recurrent ulcer bleeding. N Engl J Med. 2005; 352:238-244. [PubMed: 15659723]

23. Ndrepepa G, Berger PB, Mehilli J, Seyfarth M, Neumann FJ, Schomig A, Kastrati A. Periprocedural bleeding and 1-year outcome after percutaneous coronary interventions: Appropriateness of including bleeding as a component of a quadruple end point. J Am Coll Cardiol. 2008; 51:690-697. [PubMed: 18279731]

24. Rao SV, Dai D, Subherwal S, Weintraub WS, Brindis RS, Messenger JC, Lopes RD, Peterson ED. Association between periprocedural bleeding and long-term outcomes following percutaneous coronary intervention in older patients. JACC. Cardiovascular Interventions. 2012; 5:958-965. [PubMed: 22995883]

25. Suh JW, Mehran R, Claessen BE, Xu K, Baber U, Dangas G, Parise H, Lansky AJ, Witzenbichler B, Grines CL, Guagliumi G, Kornowski R, Wohrle J, Dudek D, Weisz G, Stone GW. Impact of inhospital major bleeding on late clinical outcomes after primary percutaneous coronary intervention in acute myocardial infarction the Horizons-AMI (Harmonizing Outcomes with Revascularization and Stents in Acute Myocardial Infarction) trial. J Am Coll Cardiol. 2011; 58:1750-1756.

[PubMed: 21996385] 
26. Spencer FA, Moscucci M, Granger CB, Gore JM, Goldberg RJ, Steg PG, Goodman SG, Budaj A, FitzGerald G, Fox KA. Does comorbidity account for the excess mortality in patients with major bleeding in acute myocardial infarction? Circulation. 2007; 116:2793-2801. [PubMed: 18025530]

27. Hochholzer W, Wiviott SD, Antman EM, Contant CF, Guo J, Giugliano RP, Dalby AJ, Montalescot G, Braunwald E. Predictors of bleeding and time dependence of association of bleeding with mortality: Insights from the trial to assess improvement in therapeutic outcomes by optimizing platelet inhibition with prasugrel--Thrombolysis in Myocardial Infarction 38 (TritonTIMI 38). Circulation. 2011; 123:2681-2689. [PubMed: 21606391]

28. Boden WE, O'Rourke RA, Teo KK, Hartigan PM, Maron DJ, Kostuk WJ, Knudtson M, Dada M, Casperson P, Harris CL, Chaitman BR, Shaw L, Gosselin G, Nawaz S, Title LM, Gau G, Blaustein AS, Booth DC, Bates ER, Spertus JA, Berman DS, Mancini GB, Weintraub WS. Optimal medical therapy with or without PCI for stable coronary disease. N Engl J Med. 2007; 356:1503-1516. [PubMed: 17387127]

29. Cohen DJ, Taira DA, Berezin R, Cox DA, Morice MC, Stone GW, Grines CL. Cost-effectiveness of coronary stenting in acute myocardial infarction: Results from the stent primary angioplasty in myocardial infarction (Stent-Pami) trial. Circulation. 2001; 104:3039-3045. [PubMed: 11748097]

30. Greving JP, Buskens E, Koffijberg H, Algra A. Cost-effectiveness of aspirin treatment in the primary prevention of cardiovascular disease events in subgroups based on age, gender, and varying cardiovascular risk. Circulation. 2008; 117:2875-2883. [PubMed: 18506010]

31. Shah SV, Gage BF. Cost-effectiveness of dabigatran for stroke prophylaxis in atrial fibrillation. Circulation. 2011; 123:2562-2570. [PubMed: 21606397]

32. Augustovski FA, Cantor SB, Thach CT, Spann SJ. Aspirin for primary prevention of cardiovascular events. J Gen Int Med. 1998; 13:824-835.

33. Gage BF, Cardinalli AB, Owens DK. The effect of stroke and stroke prophylaxis with aspirin or warfarin on quality of life. Arch Intern Med. 1996; 156:1829-1836. [PubMed: 8790077]

34. Eisenstein EL, Anstrom KJ, Kong DF, Shaw LK, Tuttle RH, Mark DB, Kramer JM, Harrington RA, Matchar DB, Kandzari DE, Peterson ED, Schulman KA, Califf RM. Clopidogrel use and long-term clinical outcomes after drug-eluting stent implantation. JAMA. 2007; 297:159-168. [PubMed: 17148711]

35. Mehta SR, Yusuf S, Peters RJ, Bertrand ME, Lewis BS, Natarajan MK, Malmberg K, Rupprecht $\mathrm{H}$, Zhao F, Chrolavicius S, Copland I, Fox KA. Effects of pretreatment with clopidogrel and aspirin followed by long-term therapy in patients undergoing percutaneous coronary intervention: The PCI-Cure study. Lancet. 2001; 358:527-533. [PubMed: 11520521]

36. Levine GN, Bates ER, Blankenship JC, Bailey SR, Bittl JA, Cercek B, Chambers CE, Ellis SG, Guyton RA, Hollenberg SM, Khot UN, Lange RA, Mauri L, Mehran R, Moussa ID, Mukherjee D, Nallamothu BK, Ting HH. 2011 ACCF/AHA/SCAI guideline for percutaneous coronary intervention: A report of the American College of Cardiology Foundation/American Heart Association task force on practice guidelines and the society for cardiovascular angiography and interventions. Circulation. 2011; 124:e574-651. [PubMed: 22064601]

37. Mauri L, Kereiakes DJ, Normand SL, Wiviott SD, Cohen DJ, Holmes DR, Bangalore S, Cutlip DE, Pencina M, Massaro JM. Rationale and design of the dual antiplatelet therapy study, a prospective, multicenter, randomized, double-blind trial to assess the effectiveness and safety of 12 versus 30 months of dual antiplatelet therapy in subjects undergoing percutaneous coronary intervention with either drug-eluting stent or bare metal stent placement for the treatment of coronary artery lesions. Am Heart J. 2010; 160:1035-1041. 1041 e1031. [PubMed: 21146655]

38. Camenzind E, Wijns W, Mauri L, Kurowski V, Parikh K, Gao R, Bode C, Greenwood JP, Boersma E, Vranckx P, McFadden E, Serruys PW, O'Neil WW, Jorissen B, Van Leeuwen F, Steg PG. Stent thrombosis and major clinical events at 3 years after zotarolimus-eluting or sirolimus-eluting coronary stent implantation: A randomised, multicentre, open-label, controlled trial. Lancet. 2012; 380:1396-1405. [PubMed: 22951082]

39. Dangas GD, Serruys PW, Kereiakes DJ, Hermiller J, Rizvi A, Newman W, Sudhir K, Smith RS Jr, Cao S, Theodoropoulos K, Cutlip DE, Lansky AJ, Stone GW. Meta-analysis of everolimus-eluting versus paclitaxel-eluting stents in coronary artery disease: Final 3-year results of the spirit clinical trials program (clinical evaluation of the Xience V everolimus eluting coronary stent system in the 
treatment of patients with de novo native coronary artery lesions). JACC. Cardiovascular Interventions. 2013; 6:914-922. [PubMed: 24050859]

40. Dennis MS, Burn JP, Sandercock PA, Bamford JM, Wade DT, Warlow CP. Long-term survival after first-ever stroke: The Oxfordshire Community Stroke project. Stroke. 1993; 24:796-800. [PubMed: 8506550] 
Figure 1A:
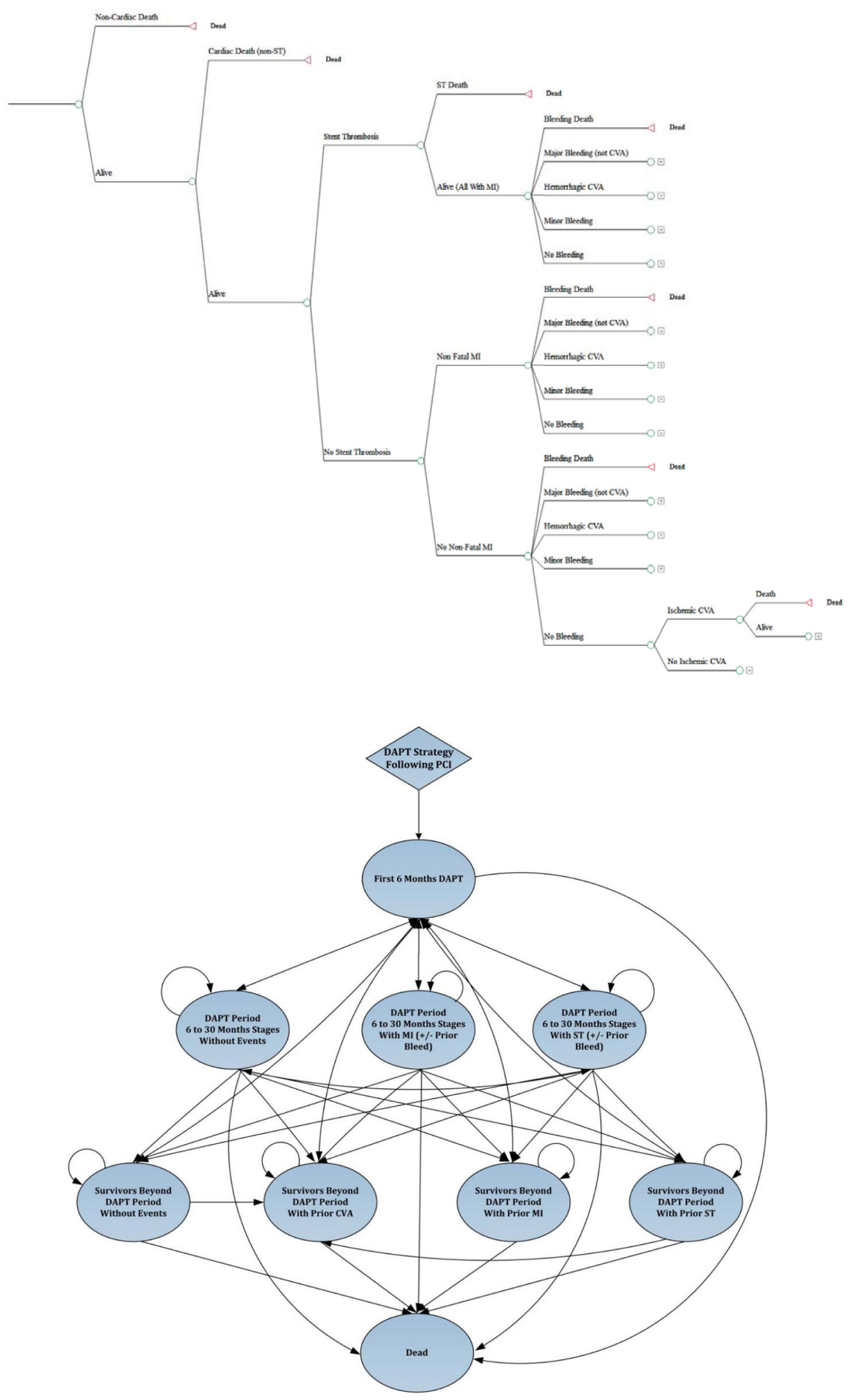

Am Heart J. Author manuscript; available in PMC 2016 February 01. 


\section{Figure 1.}

Figure 1A: Decision tree representing the outcomes in the Markov model during a given 6month cycle.

Figure 1B State-transition diagram demonstrating transitions between health states in the Markov model.

The bubble diagram represents the transitions between the health states in the model. The Markov health states are represented in the ovals with arrows indicating movement between the states from one 6-month period to the next. All patients undergo therapy with DAPT based on the strategy $(6,12$, or 30 months) and/or the presence of a prior event requiring further DAPT (e.g. ST or non-fatal MI) based on their original DAPT strategy. Each of the health states were further subdivided on the basis of presence or absence of a prior major bleeding event, but this is not shown for simplicity and brevity.

$\mathrm{CVA}=$ cerebrovascular accident, DAPT $=$ dual anti-platelet therapy, $\mathrm{MI}=$ myocardial infarction, $\mathrm{PCI}=$ percutaneous intervention, $\mathrm{ST}=$ stent thrombosis 


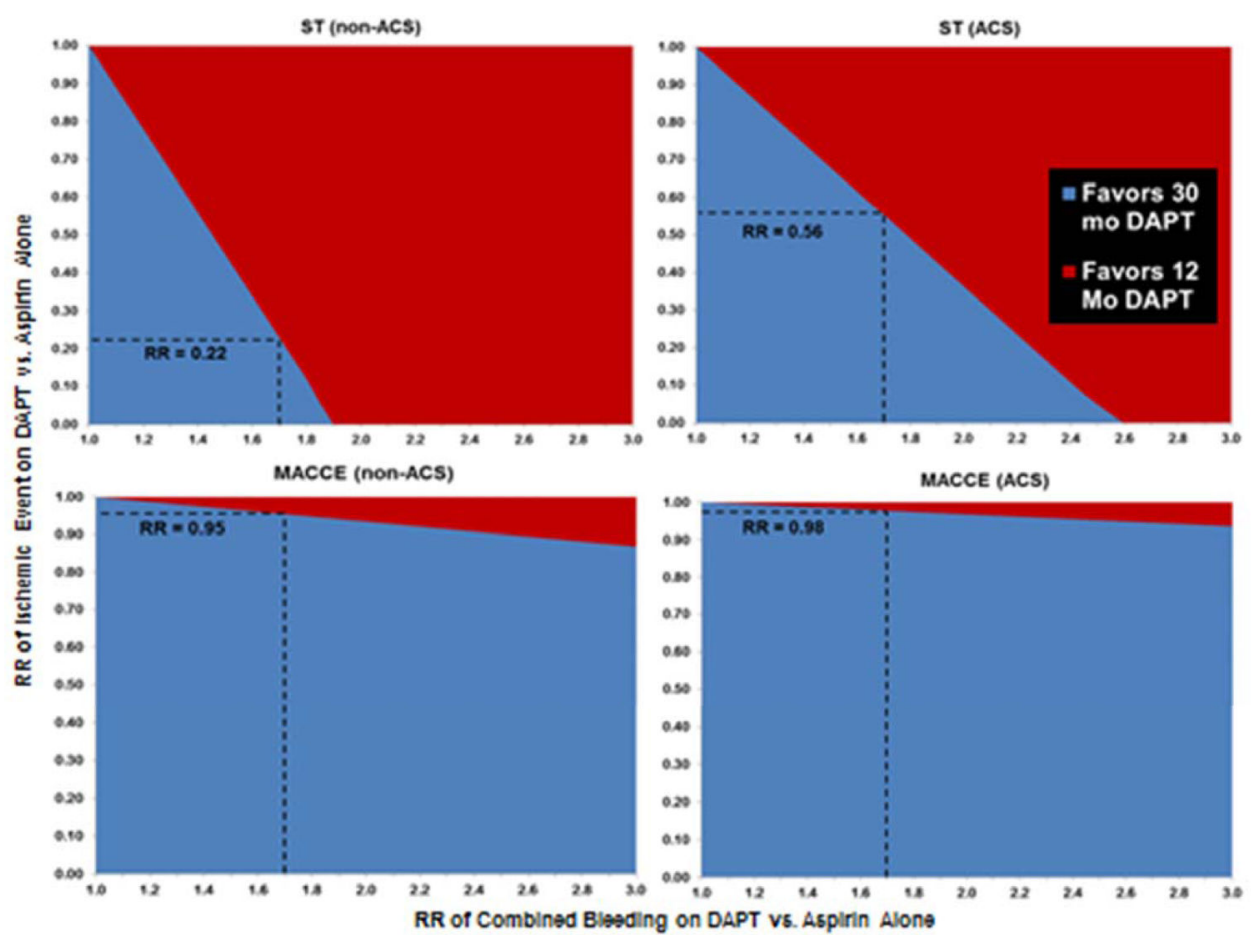

Figure 2.

(panels A-D) Two-way sensitivity analysis - Threshold relative risk (RR) of stent thrombosis (A and B) or MACCE (C and D) as a function of the risk of composite bleeding events (fatal-bleed, major and minor bleed, hemorrhagic stroke) on DAPT for DAPT durations of 12 versus 30 months in the non-ACS (A and C) and ACS (B and D) patient populations.

The threshold RR of ST on DAPT as compared to the RR of bleeding on DAPT is demonstrated for the non-ACS population (panel A) and ACS population (panel B), while the threshold RR of MACCE on DAPT as compared to the RR of bleeding on DAPT is demonstrated for the non-ACS population (panel C) and the ACS population (panel D). As the risk of bleeding events on DAPT increases, the threshold relative risk of stent thrombosis on DAPT decreases. For a given RR of bleeding for both ST and MACCE, a lesser relative risk reduction in ST is required for the ACS populations as compared to the non ACS population for 30 months of DAPT to be preferred over 12 months of DAPT after PCI. Based on our meta-analysis, the expected relative risk of bleeding on DAPT as compared to aspirin alone was 1.70. At this risk of bleeding, a RR of ST on DAPT of 0.22 in the nonACS population and 0.56 in the ACS population would be required to make 30 months of DAPT a favored approach (as denoted by the intersection of the vertical dashed line starting at a RR of bleeding of 1.70 and the horizontal line starting from the y-axis). Beyond a relative risk of bleeding on DAPT of 1.92 in the non-ACS population and 2.61 in the ACS population, no reduction in ST is sufficient to outweigh the bleeding risk. The required relative risk of MACCE on DAPT to make 30-months of DAPT preferred over 12-months of DAPT was 0.95 for the non-ACS (panel C) and 0.98 for the ACS (panel D) patient populations. Substantial increases in the risk of bleeding on DAPT had little effect on the threshold RR of MACCE needed to make longer-duration 
DAPT preferred. ACS $=$ acute coronary syndrome, $\mathrm{MACCE}=$ major adverse cardiovascular and cerebrovascular events, $\mathrm{RR}=$ relative risk, all other abbreviations same as in prior figure 
Figure 3A:

\begin{tabular}{|c|c|}
\hline Variable & Estimate \\
\hline Probability of VLST on aspirin* & $0.11 \%$ \\
\hline Probability of hemorrahgic CVA on DAPT^ ${ }^{\wedge}$ & $0.087 \%$ \\
\hline Risk of death from $\mathrm{ST}^{*}$ & $20 \%$ \\
\hline Probability of fatal bleed on DAPT^ & $0.037 \%$ \\
\hline Probability of cardiac death on aspirin alone $(>6 \mathrm{mo})^{*}$ & $0.42 \%$ \\
\hline Probability of cardiac death on aspirin alone $(0-6 \mathrm{mo})^{*}$ & $0.98 \%$ \\
\hline Probability of non-fatal $\mathrm{Ml}$ on aspirin alone $(>6 \mathrm{mo})$ & $0.46 \%$ \\
\hline Probability of major bleed on DAPT $>6 \mathrm{mor}$ & $0.26 \%$ \\
\hline Probability of ischemic CVA on aspirin alone & $0.41 \%$ \\
\hline Probability of minor bleed on DAPT ( $>6$ mo) & $0.44 \%$ \\
\hline Probability of $\mathrm{ST}$ on aspirin alone (>6 $\mathrm{mo}$ ) & $0.12 \%$ \\
\hline RR of fatal bleed with DAPT over aspirin ${ }^{\wedge}$ & 1.52 \\
\hline RR of future non-cardiac death with prior major bleed & 1.00 \\
\hline RR of hemorriagic CVA with DAPT over aspirin^ & 1.61 \\
\hline RR of cardiac death with prior ST" & 2.21 \\
\hline RR of death with prior CVA* & 9.67 \\
\hline RR of cardiac death with prior non-fatal MI" & 221 \\
\hline RR of future $S T$ with prior ST^ & 2.28 \\
\hline RR of major bleed with DAPT over aspirin alone^ & 1.77 \\
\hline RR of future non-fatal MI with prior ST or non-fatal MI & 1.00 \\
\hline Utity - Year of lito with CVA. & 0.61 \\
\hline Utilty - Year of life with prior ST^ ${ }^{\wedge}$ & 0.85 \\
\hline Utility - Year of life with CAD \& revasc. (initial)" & 0.92 \\
\hline Utily - Year of life with prior non-fata Min & 0.85 \\
\hline Disutity - Hemorthagic CVAA & 0.31 \\
\hline Disutily - $\mathrm{ST}^{*}$ & 0.07 \\
\hline Disutility - Non-fatal MI & 0.07 \\
\hline Disutilty - Minor bleeding & 0.002 \\
\hline Disutily - Ischemic CVA & 0.31 \\
\hline
\end{tabular}

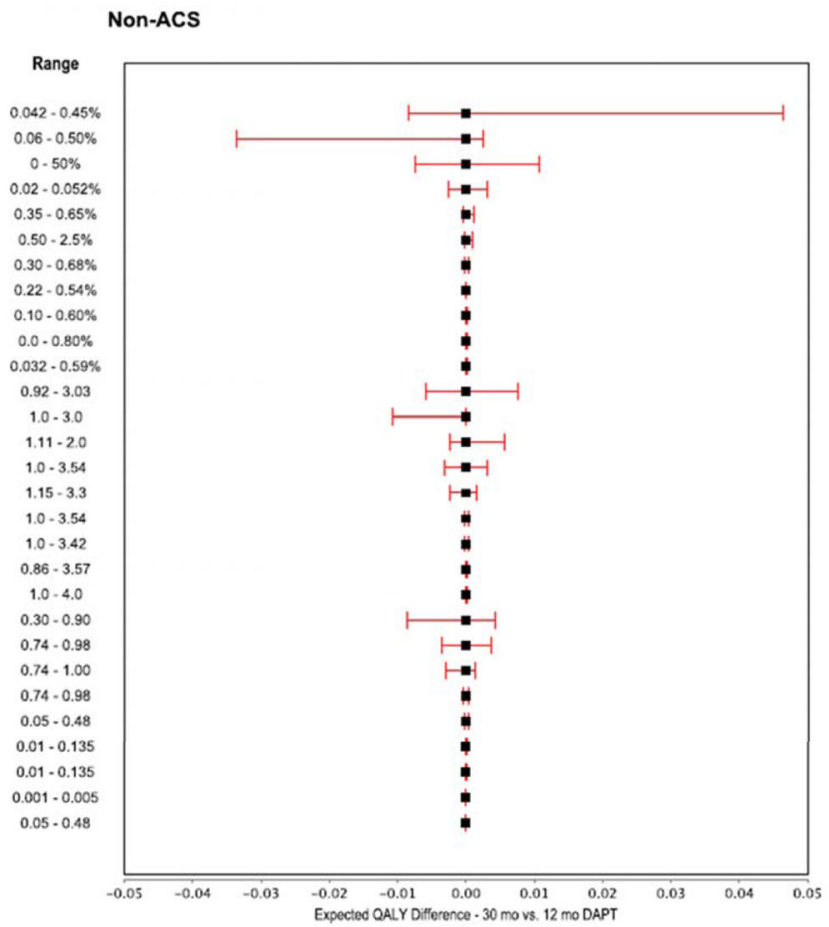

Figure 3B:

\begin{tabular}{|c|c|}
\hline Variable & Estimate \\
\hline Probability of VLST on aspirn" & $0.25 \%$ \\
\hline Probability of hemorrahgic CVA on DAPTA & $0.087 \%$ \\
\hline Risk of death from $\mathrm{ST}^{*}$ & $20 \%$ \\
\hline Probability of fatal bleed on DAPT ${ }^{\wedge}$ & $0.037 \%$ \\
\hline Probability of cardiac death on aspirin alone ( $>6 \mathrm{mo})^{*}$ & $0.92 \%$ \\
\hline Probability of cardiac death on aspirin alone $(0-6 \mathrm{mo})^{*}$ & $2.42 \%$ \\
\hline Probability of non-fatal MI on aspirin alone $(>6 \mathrm{mo})$ & $1.45 \%$ \\
\hline Probability of major bleed on DAPT $(>6 \mathrm{mo})^{4}$ & $0.26 \%$ \\
\hline Probability of ischemic $\mathrm{CVA}$ on aspirin alone & $0.41 \%$ \\
\hline Probability of minor bleed on DAPT ( $>6 \mathrm{mo})$ & $0.44 \%$ \\
\hline Probability of ST on aspirin alone (>6 mo) & $0.25 \%$ \\
\hline$R R$ of future non-cardiac death with prior major bleed & 1.00 \\
\hline RR of fatal bleed with DAPT over aspirinn & 1.52 \\
\hline RR of hemorrinagic CVA with DAPT over aspirin & 1.61 \\
\hline RR of cardiac death with prior ST. & 1.30 \\
\hline RR of death with prior CVA. & 1.67 \\
\hline RR of carciac death with prior non-fatal MI ${ }^{*}$ & 1.30 \\
\hline$R R$ of future $S T$ with prior $\mathrm{ST}^{\wedge}$ & 1.20 \\
\hline RR of future non-fatal MI with prior ST or non-fatal MI & 1.00 \\
\hline RR of major bleed with DAPT over aspirin alonen & 1.77 \\
\hline Utilty - Year of life with CVA" & 0.61 \\
\hline Utity - Year of life with prior ST^ ${ }^{\wedge}$ & 0.85 \\
\hline Utity - Year of lite with prior ACS \& revasc. (initial)" & 0.85 \\
\hline Utilty - Year of life with prior non-fata MIN & 0.85 \\
\hline Disutility - Hemorrhagic CVAN & 0.31 \\
\hline Disutility - Major bleoding^ & 0.025 \\
\hline Disutily - $\mathrm{ST}^{*}$ & 0.07 \\
\hline sutlity - Minor bleeding & 0.002 \\
\hline Disutily - Non-fatal MI & 0.07 \\
\hline Disutility - Ischemic & 0.31 \\
\hline
\end{tabular}

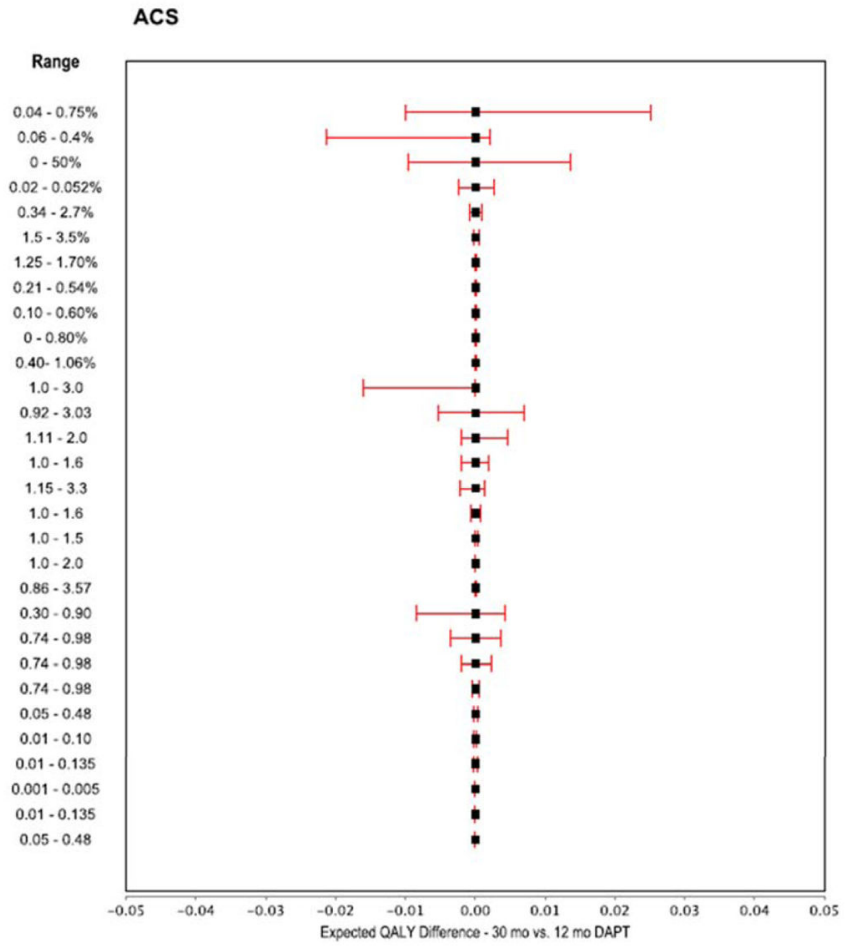

Figure 3.

Figure 3A: Forest plot showing multiple one-way sensitivity analyses (Non-ACS model). 
Figure 3B: Forest plot showing multiple one-way sensitivity analyses (ACS model). These tornado graphs demonstrates the relationship between plausible variations in key model parameters and their effect on determining whether longer-term DAPT (30 months) is preferred over 12 months therapy (using the threshold relative risk of ST with DAPT, 0.22 in the non-ACS and 0.56 in the ACS population). Each horizontal bar represents the selected variable's incremental values (30 month strategy minus 12 months) generated by varying the variable in the range represented. The model was most sensitive to variations in probabilities of VLST on aspirin, hemorrhagic CVA on DAPT, risk of death from ST, relative risks of fatal bleed with DAPT and future non-cardiac death with prior major bleed, and utility associated with prior CVA.

*The higher range values for these variables results in 30 months strategy being preferred. ${ }^{\wedge}$ Increasing values of the estimate for these variables results in 12 months strategy being preferred. $\mathrm{CI}=$ confidence interval QALY $=$ quality adjusted life years, all other abbreviations same as in prior figures 


\section{Table 1}

Baseline Probability Estimates.

\begin{tabular}{|c|c|c|}
\hline \multirow[t]{2}{*}{ Variable } & \multicolumn{2}{|c|}{ Estimate } \\
\hline & ACS & Non-ACS \\
\hline \multicolumn{3}{|c|}{ Ischemic Events not on DAPT } \\
\hline \multicolumn{3}{|l|}{ Cardiac Death } \\
\hline 0 to 6 months post-PCI & $2.42 \%$ & $0.98 \%$ \\
\hline Subsequent 6 months & $0.92 \%$ & $0.42 \%$ \\
\hline \multicolumn{3}{|l|}{ Ischemic Stroke ${ }^{\wedge}$} \\
\hline 0 to 6 months post-PCI & $0.49 \%$ & $0.45 \%$ \\
\hline Subsequent 6 months & $0.33 \%$ & $0.33 \%$ \\
\hline Risk of death & $12.0 \%$ & $12.0 \%$ \\
\hline \multicolumn{3}{|l|}{ Non-Fatal MI } \\
\hline 0 to 6 months post-PCI & $5.29 \%$ & $1.66 \%$ \\
\hline Subsequent 6 months & $1.45 \%$ & $0.46 \%$ \\
\hline \multicolumn{3}{|l|}{ Stent Thrombosis } \\
\hline 0 to 6 months post-PCI & $1.76 \%$ & $0.64 \%$ \\
\hline Subsequent 6 months & $0.25 \%$ & $0.12 \%(\text { VLST } 0.11 \%)^{\#}$ \\
\hline Risk of Death & $20.0 \%$ & $20.0 \%$ \\
\hline \multicolumn{3}{|l|}{ Bleeding Events on DAPT } \\
\hline \multicolumn{3}{|l|}{ Hemorrhagic Stroke ${ }^{\wedge}$} \\
\hline 0 to 6 months post-PCI & $0.18 \%$ & $0.12 \%$ \\
\hline Subsequent 6 months & $0.087 \%$ & $0.087 \%$ \\
\hline Post-ST ${ }^{\mathscr{I}}$ & $0.19 \%$ & $0.19 \%$ \\
\hline Risk of death & $44.0 \%$ & $44.0 \%$ \\
\hline \multicolumn{3}{|l|}{ Fatal Bleed ${ }^{\wedge} \dagger$} \\
\hline 0 to 6 months post-PCI & $0.15 \%$ & $0.042 \%$ \\
\hline Subsequent 6 months & $0.037 \%$ & $0.037 \%$ \\
\hline Post-ST ${ }^{\mathscr{I}}$ & $0.16 \%$ & $0.16 \%$ \\
\hline \multicolumn{3}{|l|}{ Major Bleed^ } \\
\hline 0 to 6 months post-PCI & $1.45 \%$ & $0.83 \%$ \\
\hline Subsequent 6 months & $0.26 \%$ & $0.26 \%$ \\
\hline Post-ST $^{I l}$ & $2.87 \%$ & $2.87 \%$ \\
\hline \multicolumn{3}{|l|}{ Minor Bleed $^{\wedge}$} \\
\hline 0 to 6 months post-PCI & $1.60 \%$ & $0.74 \%$ \\
\hline Subsequent 6 months & $0.44 \%$ & $0.44 \%$ \\
\hline Post-ST ${ }^{\mathscr{I}}$ & $2.72 \%$ & $2.72 \%$ \\
\hline Non-Cardiac Death & US Life Tables & US Life Tables \\
\hline
\end{tabular}

$\mathrm{ACS}=$ acute coronary syndrome, $\mathrm{MI}=$ myocardial infarction, $\mathrm{Mo}=$ month, $\mathrm{N} / \mathrm{A}=$ not applicable, $\mathrm{PCI}=$ percutaneous coronary intervention, $\mathrm{ST}=$ stent thrombosis, STEMI = ST-segment elevation myocardial infarction, VLST = very late stent thrombosis (beyond 12 months). 
Uniform 6-month interval event probabilities for ACS and non-ACS models for ischemic stroke and all bleeding events, $>6$ months post-PCI

\# Very late ST (beyond 12 months) in non-ACS population

${ }^{\dagger}$ Includes fatal bleeding related to both cerebrovascular and non-cerebrovascular bleeding

${ }^{I I}$ For patients who have ST as a repeat ischemic event they are assigned the same early bleeding probability as patients who suffer STEMI, after 6months the bleeding probability was the same as the general post-PCI population 


\section{Table 2}

\section{Baseline Relative Risks.}

\begin{tabular}{|c|c|c|}
\hline Variable & Model RR Estimate & Source \\
\hline Increased risk of death with prior ST & 1.30 & Garg at al. 17 \\
\hline Increased risk of death with prior non-fatal MI & 1.30 & Cole et al. ${ }^{20}$, Lloyd-Jones et al. ${ }^{21}$, \\
\hline Risk of recurrent ST with prior ST & 1.20 & Mauri et al. ${ }^{2}$ \\
\hline Increased risk of death with prior CVA & 1.67 & Dennis et al. ${ }^{40}$ \\
\hline Increased risk of bleeding on DAPT with prior major bleed & 2.46 & Chan et al. ${ }^{22}$ \\
\hline Risk of fatal bleeding on DAPT versus aspirin alone ${ }^{\dagger}$ & 1.52 & Meta-analysis (Appendix) \\
\hline Risk of hemorrhagic CVA on DAPT versus aspirin alone & 1.61 & Meta-analysis (Appendix) \\
\hline Risk of non-cerebrovascular major bleeding on DAPT versus aspirin alone ${ }^{\#}$ & 1.77 & Meta-analysis (Appendix) \\
\hline
\end{tabular}

$\mathrm{CVA}=$ cerebrovascular accident DAPT $=$ dual anti-platelet therapy, RR $=$ relative risk, all other abbreviations same as in prior table

${ }^{\dagger}$ Includes fatal bleeding related to both cerebrovascular and non-cerebrovascular bleeding

\# Includes both major and minor bleeding 
Table 3

Quality of Life Adjustments.

\begin{tabular}{lcl}
\hline Variable & Model Estimate & Source \\
\hline Year of life with stable CAD and revascularization & 0.92 & Boden et al. $^{28}$ \\
Year of life with CAD following MI and revascularization & 0.85 & \multicolumn{1}{c}{ Cohen et al. ${ }^{29}$} \\
Year of life with CVA & 0.61 & Gage et al. ${ }^{33}$, Gerving et al. ${ }^{30}$ \\
Net Disutility & & \\
$\quad$ Stent thrombosis & 0.07 & Cohen et al. $^{29}$ \\
$\quad$ Non-fatal MI & 0.07 & Cohen et al. $^{29}$ \\
$\quad$ Stroke & 0.31 & Gerving et al. ${ }^{30}$, Augustovski et al. ${ }^{32}$ \\
$\quad$ Major bleed & 0.025 & Augustovski et al. ${ }^{32}$, Shah et al. ${ }^{31}$ \\
$\quad$ Minor bleed & 0.002 & Shah et al. ${ }^{31}$ \\
\hline
\end{tabular}

$\mathrm{CAD}=$ coronary artery disease, all abbreviations same as in prior tables 


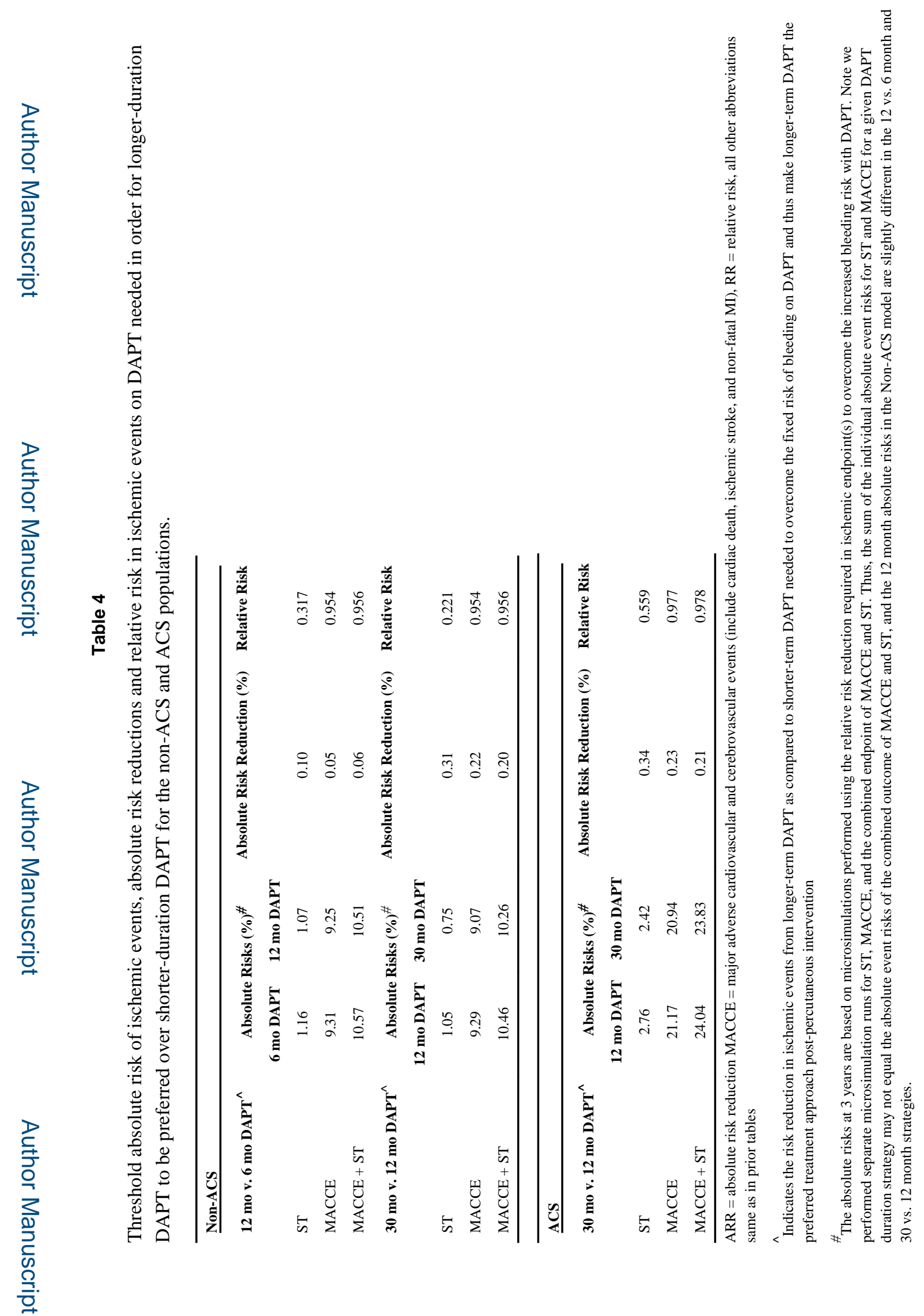

Am Heart J. Author manuscript; available in PMC 2016 February 01. 